\title{
DEVELOPMENT OF AN IMPROVED INSTALLATION PROCEDURE AND SCHEDULE OF RVI MODULARIZATION FOR APR 1400
}

\author{
DO-YOUNG KO \\ Nuclear Engineering \& Technology Institute \\ 25-1, Jang-dong, Yuseong-gu, Daejeon, 305-343, KOREA \\ "Corresponding author. E-mail : kodoyoung@khnp.co.kr
}

Received July 16, 2010

Accepted for Publication September 17, 2010

The construction technology for reactor vessel internals (RVI) modularization is one of the most important factors to be considered in reducing the construction period of nuclear power plants. For RVI modularization, gaps between the reactor vessel (RV) core-stabilizing lug and the core support barrel (CSB) snubber lug must be measured using a remote method from outside the RV. In order to measure RVI gaps remotely at nuclear power plant construction sites, certain core technologies must be developed and verified. These include a remote measurement system to measure the gaps between the RV core-stabilizing lug and the CSB snubber lug, an RVI mockup to perform the gap measurement tests, and a new procedure and schedule for RVI installation. A remote measurement system was developed previously, and a gap measurement test was completed successfully using the RVI mockup. We also developed a new procedure and schedule for RVI installation. This paper presents the new and improved installation procedure and schedule for RVI modularization. These are expected to become core technologies that will allow us to shorten the construction period by a minimum of two months compared to the existing installation procedure and schedule.

KEYWORDS : RVI Modularization, Installation Procedure, Installation Schedule, APR1400, RVI Mockup

\section{INTRODUCTION}

Recently, many research groups throughout the world have conducted extensive research regarding methods of shortening the construction period of nuclear power plants to less than 50 months. The installation period of the reactor vessel $(\mathrm{RV})$ is about $8-10$ months [1]. The reactor vessel internals (RVI) can modularize the installation of the core support barrel (CSB) and lower support structure/core shroud (LSS/CS) [2]. For modularization of the CSB and LSS/CS, RVI modularization, gaps between the RV core-stabilizing lug and the CSB snubber lug must be measured using a remote method from outside the RV [3]. Fig. 1 shows existing method and modularization method of RVI installation [4].

For RVI modularization, a remote measurement system must be developed and functional tests of the system must also be performed using a RVI mockup to verify reliability at construction sites. Finally, a new installation procedure and schedule for RVI modularization must be developed to reduce the construction time. We developed a remote measurement system, designed and fabricated a RVI

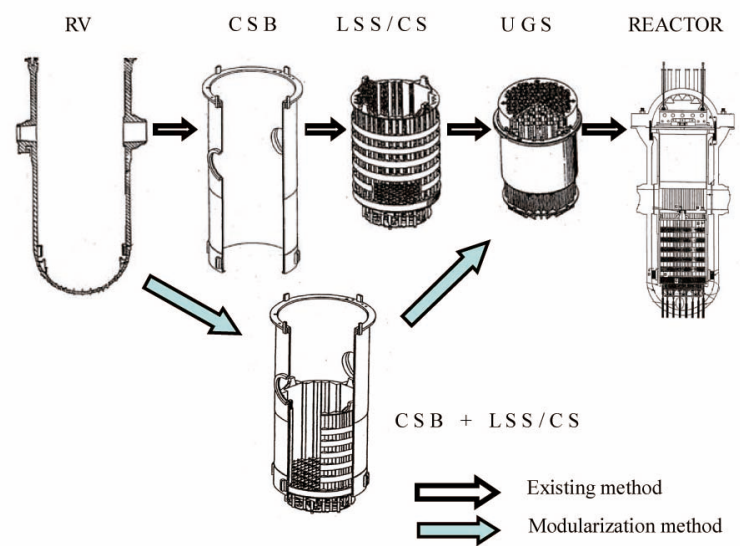

Fig. 1. Existing Method and Modularization Method of RVI Installation

mockup, and then successfully completed a gap measurement test using the RVI mockup [5]. Fig. 2 and Fig. 3 show the designed 3D model and a depiction of the 
RV mockup. In addition, Fig. 4 and Fig. 5 show the designed 3D model and a depiction of the CSB mockup.

This paper describes an improved installation procedure and schedule for RVI modularization for Advanced Power Reactor 1400 (APR1400).

Development of an improved installation procedure for RVI modularization is presented in chapter 2, in which the feasibility of the improved installation procedure was validated by experiments using a remote measurement system and a RVI mockup.

Development of an improved installation schedule for RVI modularization is described in chapter 3, in which the value of the improved installation schedule was verified by analysis of the existing RVI installation process at the Shin-kori \#1 nuclear power plant.

\section{DEVELOPMENT OF AN IMPROVED INSTALLATION PROCEDURE FOR RVI MODULARIZATION}

Table 1 shows the effects of the improved installation procedure for RVI modularization developed in this study. Under the existing installation procedure, six snubber shims were assembled between the RV core-stabilizing lugs and the CSB snubber lugs after alignment of the CSB and the RV. Subsequently, assembly and flexure welding of the LSS and the CS were conducted. The new and

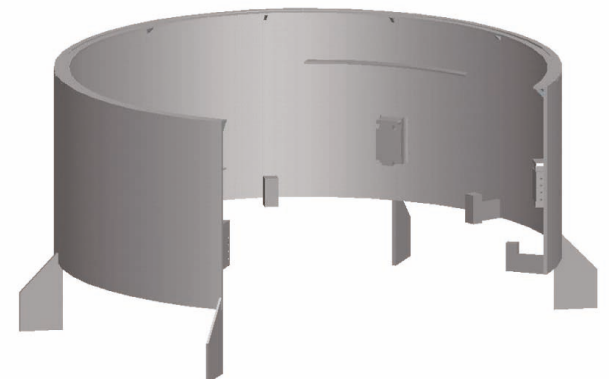

Fig. 2. 3D Model of RV Mockup

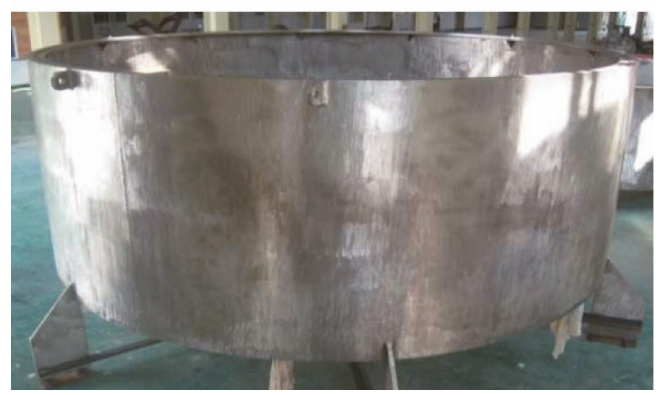

Fig. 3. Picture of Manufactured RV Mockup improved installation procedure for RVI modularization was developed through this study, allowing assembly and flexure welding of the LSS and the CS to be performed before the main installation process. Alignment of the CSB assembly and the RV and assembly of the snubber shims were undertaken during the main installation process.

The improved installation procedure for RVI modularization in this study appears in Table 1 as order 1 and order 3. A detailed explanation is given below of the flexure welding of the LSS and the CS in the CSB as well as of the alignment and installation of the snubber shims of the CSB assembly and the RV.

\subsection{Alignment of the CSB and RV and Calculation of the Dimensions of the Snubber Shim}

1) The dimensions between the RV outlet nozzle and the reactor coolant loop (RCL) were measured after the welding of the RCL. They were recorded along with the measured dimensions before the welding. The widths of the RV core-stabilizing lugs were also measured.

2) The measured positions were marked on RV keyways and the relative positions of the keyways on the RV centerline were measured using the widths and vertical degrees.

3) The target-hole positions of the RV flange on the RV centerline and the dimensions of the gauge blocks of

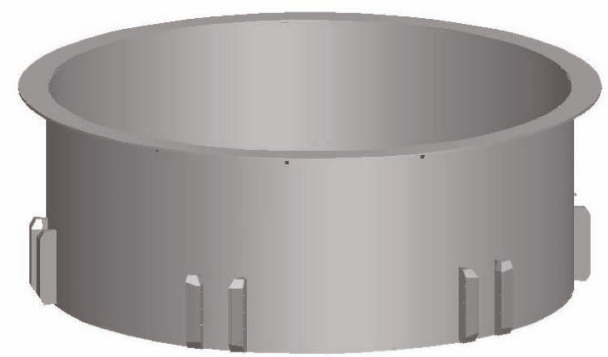

Fig. 4. 3D Model of CSB Mockup

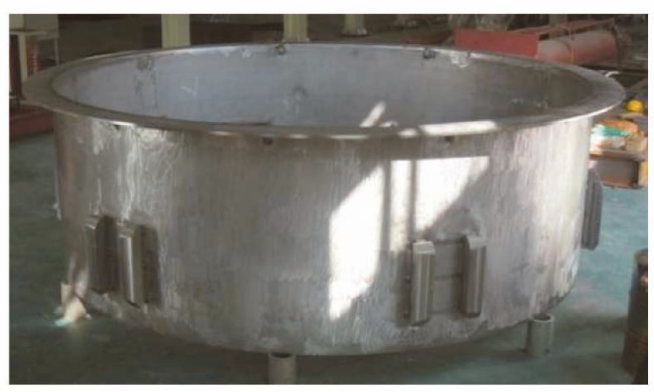

Fig 5. Picture of Manufactured CSB Mockup 
the RV core stabilizing lug were also measured. Here, the dimensions of the required measurements were the heights and widths of the gauge blocks.

4) Before installation of the gauge blocks, the integrity of the RV core-stabilizing lugs and the cap screws was checked. Neolube, a dry film lubricant, was applied twice on both the threaded surfaces on the cap screws and the surfaces of the bearings.

\subsection{Installation of the Gauge Block}

1) Gauge blocks were installed and the cap screws were then tightened. They needed to be tightened according to a three-step tightness method, as follows: 160, 213 and $266 \mathrm{ft}-\mathrm{lbs}$. The final torque was $256-276 \mathrm{ft}-\mathrm{lbs}$ and the tightness sequence was as follows:

2) The number of cap screws was $1,2,3$, and 4 from top to bottom. The tightness sequence of step 1 was $2,3,1$, and 4 , and the torque was $160 \mathrm{ft}-\mathrm{lbs}$.

3 ) The tightness of step 2 was identical to that of 2) and the torque was $213 \mathrm{ft}-\mathrm{lbs}$.

4) The tightness of step 3 was identical to that of 2) and the torque was $266 \mathrm{ft}-\mathrm{lbs}$.

5) The cap screws were unscrewed in the reverse sequence of the tightness sequence: $4,1,3$, and 2 .

6) One more time, the tightness was carried out by the sequence of 2), 3), and 4).

7) The remaining gauge blocks were installed on the CSB snubber lugs according to the sequence of 2), 3), 4), 5), and 6). After installation of the gauge blocks, the gaps between the upper part and the lower part were uniformly maintained at $0.1016 \mathrm{~mm}$.

\subsection{Dimensions of the CSB Snubber Lug}

1) After installation of the gauge blocks, all widths of the gauge blocks at the same six intervals were measured. Subsequently, the dimensions of the CSB snubber lugs were measured. The measured parts of the CSB snubber lugs were the inside widths of both of their surfaces. In total, six holes of the CSB snubber lugs were measured.

2) The measured positions of the CSB keyway were marked and the widths measured.

3) Four dummy alignment keys (DAKs) were installed on the RV keyways and adjusted so that they could be positioned within $0.254 \mathrm{~mm}$ of the RV centerline. The vertical degree of an RV head seating surface of a DAK was adjusted so that it could be positioned within $0.0254 \mathrm{~mm} / \mathrm{ft}$. The position of the DAK and the vertical degree were measured again.

\subsection{Installation of the Remote Measurement System}

1) In order to set up the remote measurement system inside the CSB assembly, three channel boxes were mounted in the CSB assembly. As shown in Fig. 6,

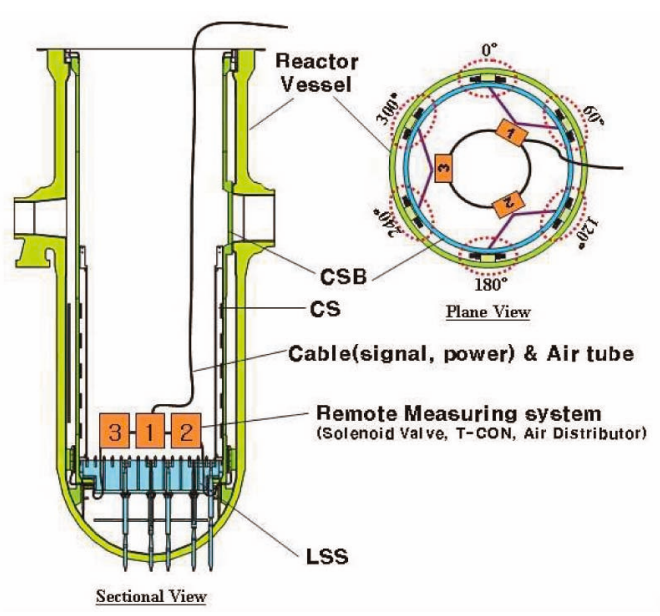

Fig 6. Setup Position of the Remote Measurement System

Table 1. Improved Installation Procedure for RVI Modularization

\begin{tabular}{c|l|c}
\hline Order & \multicolumn{1}{|c}{ RVI installation procedure } & Remark \\
\hline 1 & Assembly of the LSS and the CS in the CSB, Flexure welding & Improvement \\
\hline 2 & Welding of the flow baffle in the RV & Improvement \\
\hline 3 & Alignment of the CSB assembly and the RV, Installation of snubber shims & \\
\hline 4 & Installation of the CSB assembly in the RV & \\
\hline 5 & Installation and alignment of the UGS & \\
\hline 6 & Installation and alignment of the RV head & \\
\hline 7 & Installation of alignment keys, dowel pins and guide lugs insert & \\
\hline
\end{tabular}




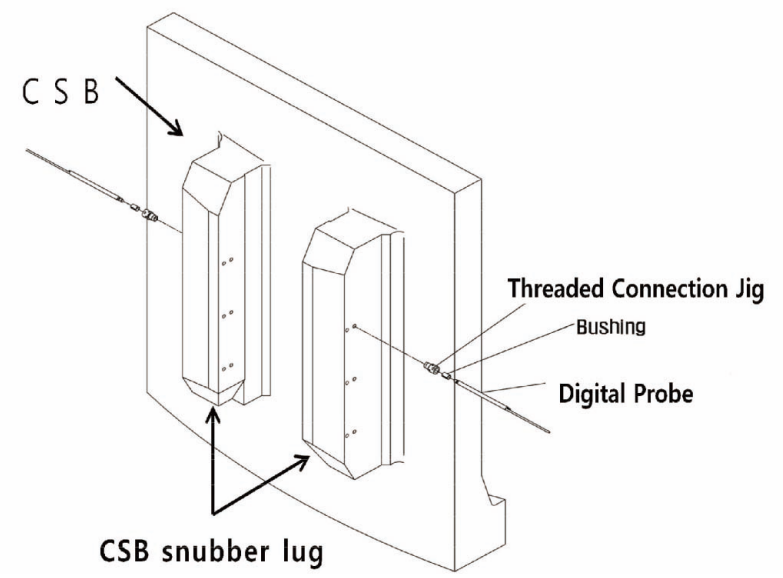

Fig 7. Assembly of Digital Probe and Threaded Connection Jig the channel boxes were opened and 72 digital probes were taken out of the CSB assembly through spaces between the CSB and the LSS.

2) As shown in Fig. 7, all 72 digital probes were installed the holes of the CSB snubber lugs after the digital probes were assembled with the threaded connection jigs. For this step, the digital probes were necessarily placed at $1 \mathrm{~mm}$ or more from the measured holes of the CSB snubber lug. Bolt tightening was done using a hexagonal wrench. The bolts numbered $1,2,3$, and 4 were clockwise and the tightening order was $1,3,2$, and 4 . All remaining sensors were installed via the methods described above.

3) The electric power cords, air hoses, and signal cables between the channel boxes were connected and taken out of the RV. The air hoses were connected with an

Table 2. Remote Measurement System Guideline

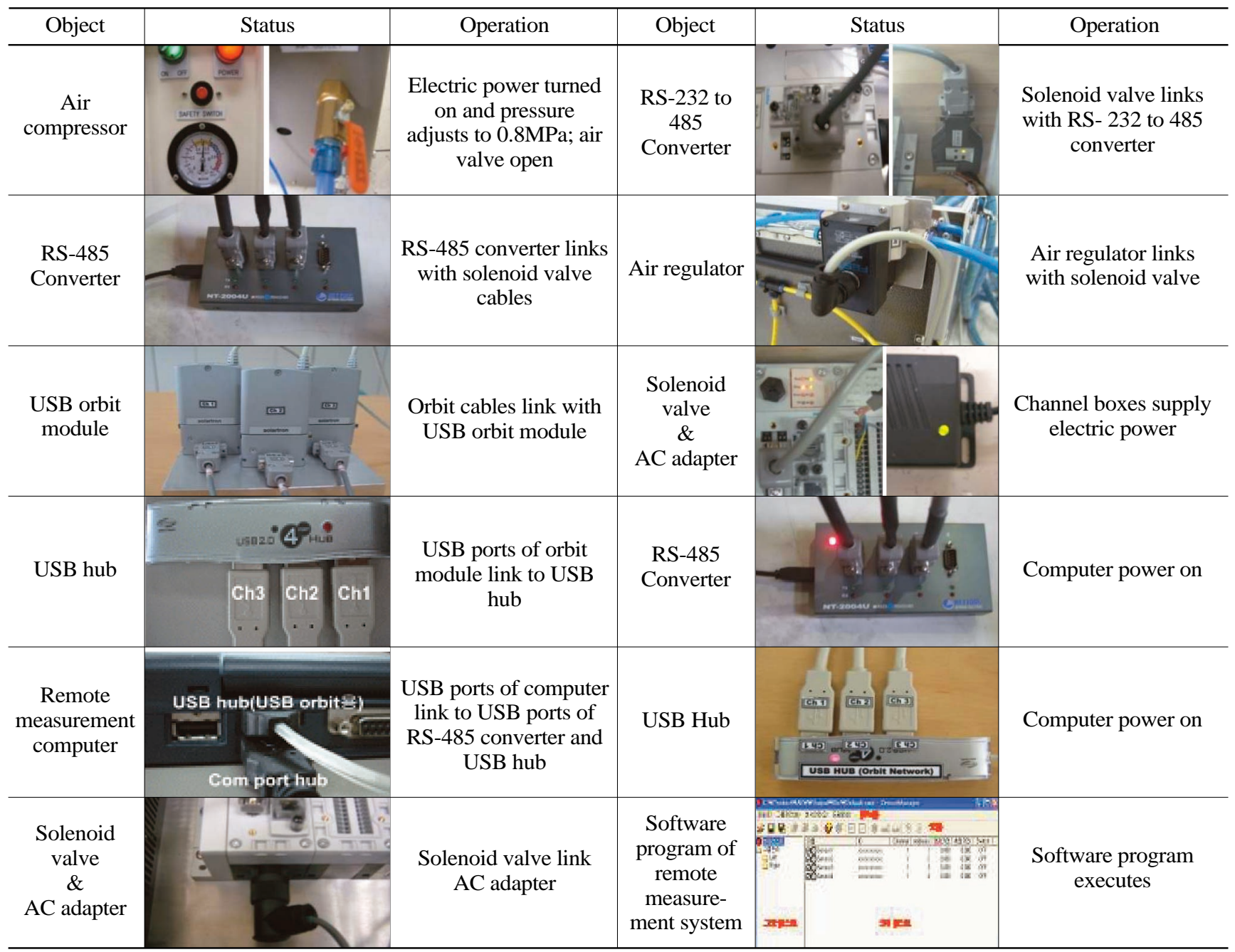


air compressor.

4) The signal cables were linked with a USB-orbit module and an RS-485 converter. The USB ports of the USBorbit module were linked with a USB hub. The USB hub and USB ports of the RS-485 converter were connected to the USB ports of a remote measurement computer. Table 2 shows the remote measurement system guideline.

5) Electric power supplies were checked in order with the remote measurement system first, followed by the air compressor, and then the remote measurement computer to verify whether or not the connections worked exactly according to the operating guide.

6) The air pressure was set to $0.8-1$ bar using a software program on the remote measurement computer. At this stage, the digital probes had to be checked using a software program to verify whether or not they operated normally. Fig. 8 shows the configuration of the remote measurement system.

\subsection{Zero-Point Adjustment of the Remote Measurement System and Marking}

1) In order to attach a zero-point adjustment device firmly onto the CSB snubber lug, a zero-point adjustment plate and a connector on the gap control section were tightened. The remaining zero-point adjustment devices adhered to the CSB snubber lug as described above. Fig. 9 shows the zero-point adjustment device mounted on the CSB snubber lug.

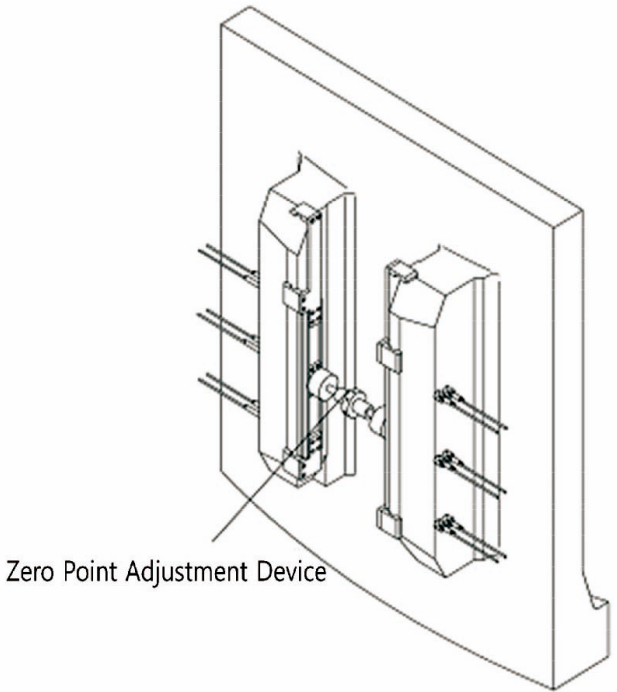

Fig 9. Installation of Zero Point Adjustment Device

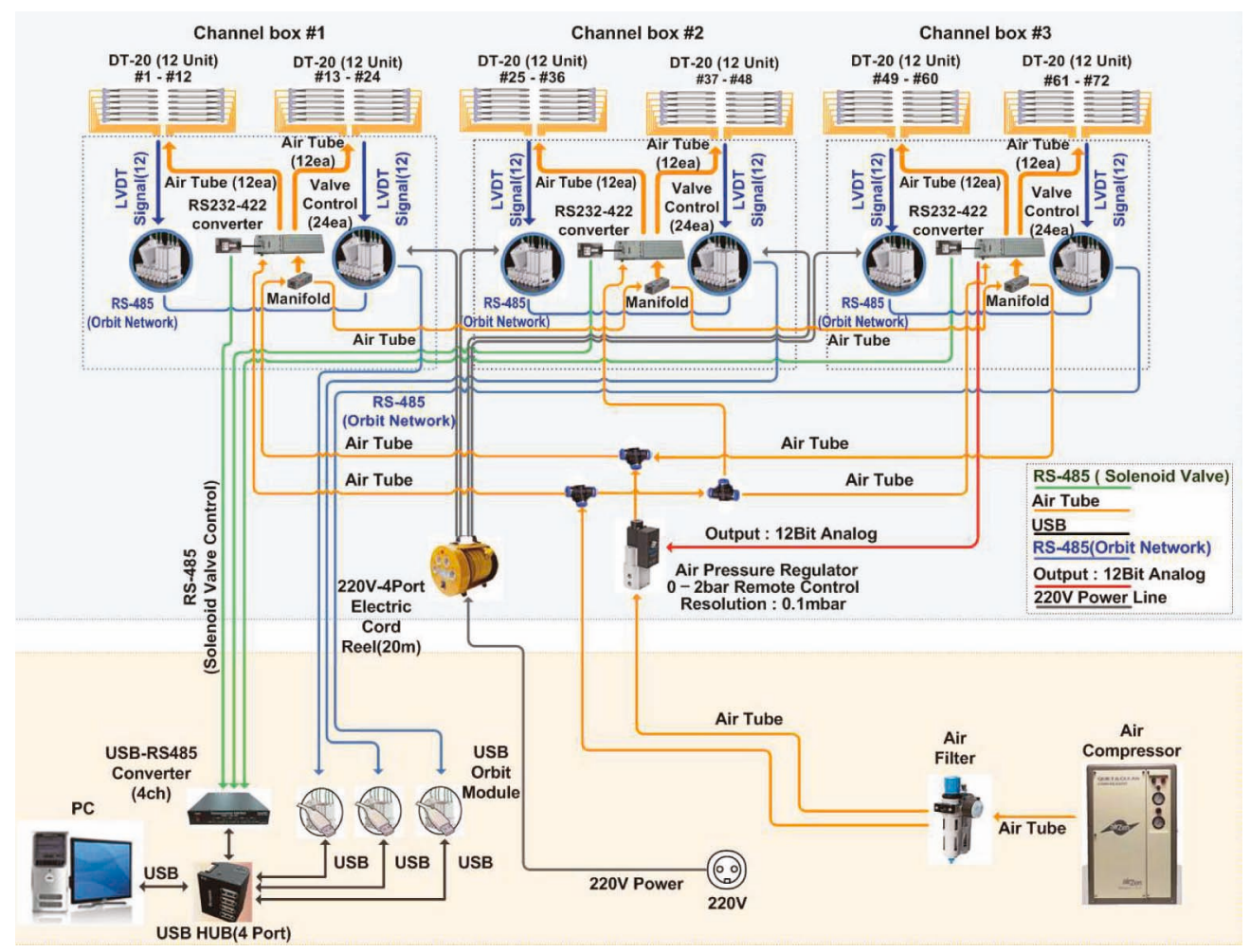

Fig. 8. Configuration of the Remote Measurement System 
2) Length measurement was done using the software program of the remote measurement computer. Measurements were taken five times. The average values were then used to set the zero-point data. When the setting of the zero-point data was complete, the zero-point data were saved and recorded.

3) The zero-point adjustment device was detached from the CSB snubber lug and a marking tool was attached to the CSB snubber lug. Digital probes were stained with a red stamping ink and their correct operation was confirmed using the software program of the remote measurement computer. The remaining digital probes were executed in the same way.

4) The marking tool was removed from the CSB snubber lug and the channel boxes in the CSB assembly and air compressor were then separated from the air hoses, electric power cords, and signal cables connected to the remote measurement computer. The disconnected cords and cables had to be arranged so that a disturbance did not result from the combination of the RV and the CSB assembly. Fig. 10 shows the marking tool assembly attached onto the CSB snubber lug.

\subsection{Combination of the CSB Assembly and the RV}

1) The CSB assembly was aligned to the RV centerline and the CSB assembly was inserted in the RV. The CSB assembly was turned at $45^{\circ}$ and was lowered to prevent damage to the DAK. It was then combined after the CSB assembly was turned to the original position before ensuring a $50 \mathrm{~cm}$ interval between the CSB assembly and the RV.

2) When the CSB assembly was installed, the load measured by a hydra-set was continuously checked.

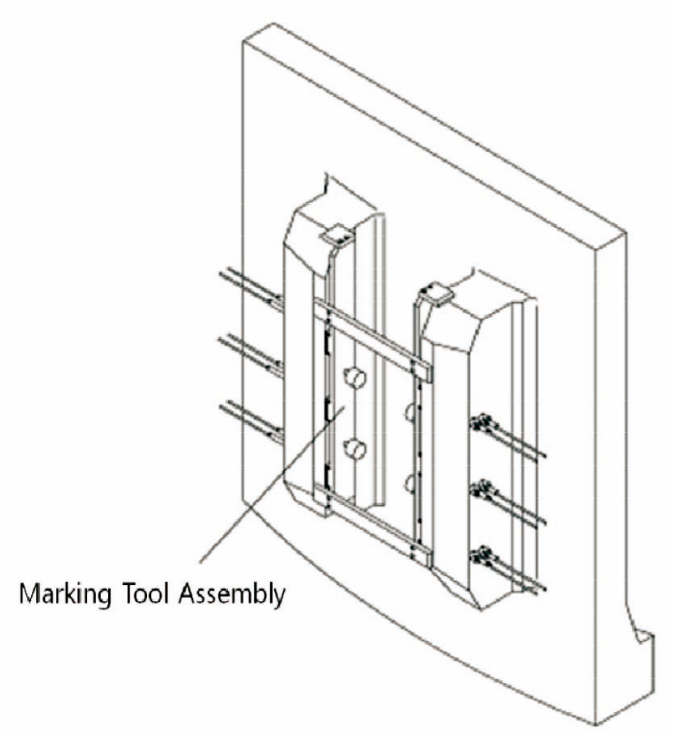

Fig 10. Installation of a Marking Tool
In addition, when the CSB assembly was at a height of approximately $30 \mathrm{~cm}$ from the RV head seating surface, the bottom surface (datum "B") of the CSB upper flange was used to stop the descent of the CSB assembly. A basis surface (datum "B") of the CSB upper flange was used for a parallel adjustment to within $0.381 \mathrm{~mm}$ of the RV head seating surface.

3) The load of the hydra-set was decreased to $10,000 \mathrm{lb}$ and was checked given that the CSB came in contact with the RVI installation surface. The RV centerline and the CSB centerline were aligned within 0.0254 $\mathrm{mm}$ by CSB position devices ( $8 \mathrm{EA}$ ).

4) The vertical degree for the CSB keyway and the datum hole were measured and their relative positions on the CSB centerline were confirmed.

5) The gaps between the RV head seating surface and the upper surface of the CSB flange were measured in $45^{\circ}$ intervals. The gaps $(2.1336-2.9464 \mathrm{~mm})$ of the RV outlet nozzle and the temperatures of the nozzle area were also measured.

6) The alignment of the RV/CSB centerline and the requirements of the nozzle gap were checked. If the requirements were not satisfied, it was necessary to repeat this procedure. If the position of the DAK changed before and after the installation of the CSB due to the checking of the position of the DAK, the measurements had to be done again and the existing checklist was invalidated. All installation requirements were met; the final adjustment conditions and the variation of the CSB centerline on the RV centerline were measured and recorded.

\subsection{Length Measurement Using the Remote Measurement System}

1) The channel box of the internal CSB and the air hose, compressor, electric power cord, power supply and signal cables of the external CSB were connected. Electric power was then supplied.

2) Using a software program running on a remote measurement computer, the length was measured a total of five times. The pressure for the measurement was adjusted to $0.8 \sim 1 \mathrm{bar}$; this was set to have a zero length to ensure that the data were entered correctly. The average value of the measured lengths was used as the data. Once the measurement was completed, the data were stored and the measured length was recorded.

3) After the gap measurements were completed, all electric power was turned off. After the RV and the CSB assembly were detached, the air hose, electric power cord and signal cable were respectively separated from the compressor, electric power, USB hub and RS-485 converter. Once separated, the air hose, electric power cord and signal cable were temporarily fixed in the CSB assembly to ensure that they would not interfere with the disassembly of the CSB assembly. 


\subsection{Separation of the CSB Assembly and RV}

1) The CSB assembly was separated from the RV and set on a storage stand. The CSB assembly was lifted at $45^{\circ}$ turns after vertical lifting of approximately $50 \mathrm{~cm}$ in order to prevent the DAKs from being damaged. The CSB assembly was checked continuously via a load measured by a hydra-set.

2) After the checked positions of the gauge blocks were marked using digital probes, the widths of the marked positions were measured. After removing the gauge blocks, the gaps between the CSB snubber lugs and the RV core-stabilizing lugs were used to calculated the processing dimensions of the snubber shims; the gaps were calculated at $0.381-0.508 \mathrm{~mm}$ as a permissible range [4].

\subsection{Installation and Measurement of the Shim on the RV Core-Stabilizing Lug}

1) The dimensions of the refined shims were measured and a penetration test was conducted. Before installation of the shims, the RV core stabilizing lugs and the cap screws were checked to confirm the integrity of each screw. Neolube, a dry film lubricant, was applied twice to the threaded surfaces of the cap screws and bearing surface. Fig. 11 shows the assembly of the snubber shims on the RV core-stabilizing lug.

2) When the shims were installed, the cap screws were assembled by hand and tightened according to a three-step tightness method: 160, 213 and $266 \mathrm{ft}-\mathrm{lbs}$. It was important that after the shims were installed, the upper gaps and lower gaps were maintained as constant $(0.1016 \mathrm{~mm})$.

3) After the shims were installed, their full widths were measured in six positions to measure the equal intervals.

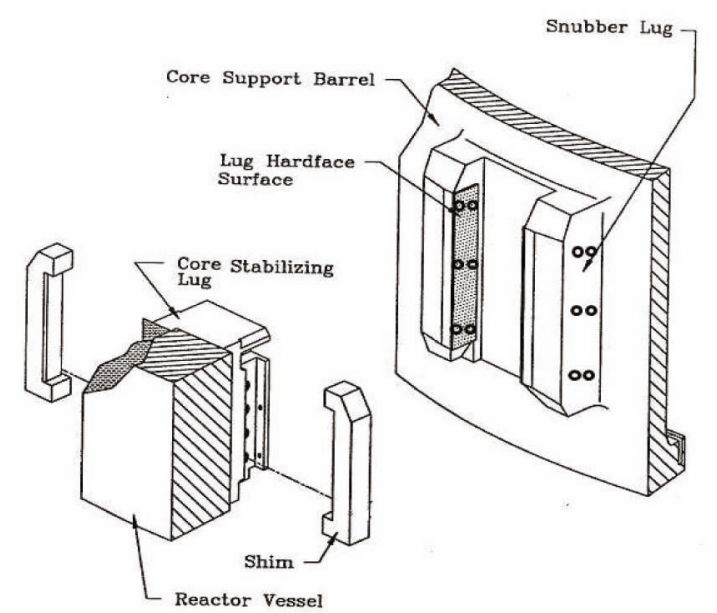

Fig 11. Assembly of Snubber Shims on the RV CoreStabilizing Lug
The DAKs were adjusted to vertical degrees at 0.0254 $\mathrm{mm} / \mathrm{ft}$ for the RV head seating surface. At this point, the vertical degrees of the DAKs and the status of the installed positions were recorded.

4) According to section 2.6 "Combination of the CSB assembly and the RV," the CSB assembly was installed in the RV. When the RV core-stablizing lugs and the RV snubber shims were connected, they were lowered using the hydra-set. The RV centerline and the CSB centerline were adjusted within $0.0254 \mathrm{~mm}$ using the DAKs, and the CSB assembly was completely lowered. If the positions of the DAKs changed, the measurements had to be done again.

5) The gaps between the RV and the CSB outlet nozzles were recorded and the offsets of the CSB keyways regarding the DAKs were recorded as well. The offsets of the CSB centerline in relation to the RV centerline were also calculated and recorded.

6) The air hoses, electric power cords and signal cables of the remote measurement system were reconnected to the compressor, electric power, USB hub and RS-485 converter, and electric power was supplied. The length of the snubber shims was measured five times. Once the measurement was complete, the measured data were stored and the measured lengths were recorded. The measured lengths of the shims were confirmed to be within a permissible range $(0.381-0.508 \mathrm{~mm})$. If the measured lengths of the shims exceeded the permissible range, they would be used after reprocessing.

7) All electric power was turned off, and the air hoses, electric power cords, and signal cables were respectively separated from the compressor, electric power, USB hub and RS-485 converter. Separated air hoses, electric power cables and signal cables were temporarily fixed in the CSB assembly when the RV and CSB assembly were detached in order to avoid interference with cables and pieces of equipment. Finally, the gaps between the CSB and the RV core-stop lugs were measured.

\subsection{Separation and Confirmation of the Remote Measurement System}

1) The CSB assembly was separated from the RV and set down on a storage stand. The channel boxes and digital probes, threaded connection jigs, air hoses, electric power cables, and signal cables were completely removed from the CSB assembly.

2) After removing the CSB assembly, snubber shims were confirmed in the combined state. All heads of the cap screws were dug with holes of $\Phi 3.0226 \mathrm{~mm}$ at a depth of $19.05 \pm 0.762 \mathrm{~mm}$.

3) All holes of the heads of the cap screws had pins inserted and their installation status was checked. Plugs ( $\Phi 12.7 \mathrm{~mm}$ ) installed to fix the pins were inserted; after welding the plugs, penetration tests were carried out. 


\section{DEVELOPMENT OF IMPROVED INSTALLATION SCHEDULE FOR RVI MODULARIZATION}

Table 3 presents a comparison of the existing RVI installation process at the Shin-kori \#1 nuclear power plant and the modularization installation process developed in this study. Compared with the existing method, it was found that the developed installation process using RVI modularization can shorten the installation period to about 67 days in the critical path. This can reduce the construction period, as follows: RV \& CSB dimension check (15 days), CSB alignment \& gap measurement (13 days), RV \& CSB $\&$ LSS/CS alignment (13 days), flexure welding (20 days) and CSB assembly installation \& alignment check (6 days).

The RV \& CSB dimension check (15 days), flexure welding (20 days) and CSB assembly installation \& alignment check (6 days) are conducted through a concurrent process before the determination of the critical path in the existing installation process. In addition, the CSB module alignment \& gap measurement (13 days) and RV \& CSB module alignment (13 days) are correspondingly reduced using the remote measurement system and the improved installation procedure developed in this study.

Fig. 12 shows the existing RVI installation schedule in the critical path at the Shin-kori \#1 nuclear power plant in Korea. It consists of the following steps: (1) the RV \& CSB dimension check (2) the CSB alignment \& gap measurement (3) snubber shim machining \& installation (4) the RV \& CSB \& LSS/CS alignment (5) flexure welding (6) the CSB assembly installation \& alignment check and (7) the upper guide structure (UGS) \& RV head installation \& alignment check. Therefore, we determined that the RVI installation period at the Shin-kori \#1 nuclear power plant should require approximately 129 days in the critical path.

Fig. 13 shows the RVI modularization installation schedule developed in this study.
To use RVI modularization in an actual construction project, we developed modularization installation schedule. The RVI modularization schedule in the critical path consists of the following steps: (1) CSB module alignment \& gap measurement (2) snubber shim machining \& installation (3) RV \& CSB module alignment (4) and UGS \& RV head installation \& alignment check. Therefore, it was determined that the RVI modularization installation period should require about 62 days in the critical path.

\section{RESULTS}

An improved installation procedure and schedule for RVI modularization were developed in this study. These developments facilitated a RV \& CSB dimension check, flexure welding of the LSS and the CS in the CSB and a CSB assembly installation \& alignment check before the main installation process. The new procedure and schedule also facilitated a CSB alignment \& gap measurement and a RV \& CSB module alignment, as undertaken during the main installation process.

According to the improved installation procedure for RVI modularization, the gaps between the RV corestabilizing lug and the CSB snubber lug of the RVI mockup are measured by a remote measurement method. The results measured by these methods are analyzed with design shims attached to the assembly between the RV core-stabilizing lug and the CSB snubber lug. We found that the measured gap values satisfied the requirements within the permissible range, $0.381-0.508 \mathrm{~mm}$, after the shims on the RV core-stabilizing lug were installed.

\section{DISCUSSION}

Many research groups throughout the world have studied ways to shorten the construction period of nuclear

Table 3. Comparison of Existing RVI Installation Period and Modularization Installation Period

Unit. Day

\begin{tabular}{l|c|c}
\hline & $\begin{array}{c}\text { Existing Method } \\
\text { (Ex. Shin-kori \#1, Korea) }\end{array}$ & Proposed Modularization Method \\
\hline RV \& CSB Dimension Check & 15 & - \\
\hline CSB Alignment \& Gap Measurement & 18 & CSB Module Alignment \& Gap Measurement (5) \\
\hline Snubber Shim Machining \& Installation & 21 & 21 \\
\hline RV \& CSB \& LSS/CS Alignment & 28 & RV \& CSB Module Alignement (15) \\
\hline Flexure Welding & 20 & - \\
\hline CSB Assembly Installation \& Alignment Check & 6 & - \\
\hline UGS \& RV Head Installation \& Alignment Check & 21 & 21 \\
\hline
\end{tabular}


power plants [6]-[16]. RVI modularization is one of the most important factors to be considered to reduce construction time. The installation of a nuclear reactor requires 8 - 10 months for the critical path of construction in nuclear power plants [1]. To modularize the RVI, the gaps between the RV core-stabilizing lug and the CSB snubber lug must be measured using a remote method from outside the RV. To measure the RVI gaps remotely for RVI modularization, several requirements should be satisfied, the first being the development of the remote measurement system, the second being the design and fabrication of mockup to perform the gap measurement test, and the third being the development of the new installation procedure and schedule. We developed a remote measurement system and successfully completed the gap measurement test using the RVI mockup [17]. A new installation procedure and schedule for RVI modularization were also developed in this paper. Thus, advanced technologies for RVI modularization including the developed installation procedure and schedule are expected to reduce the construction time by a minimum of two months compared to the existing installation procedure and schedule. We also expect that the construction budget will be reduced by a minimum of $\$ 197$ million for the next construction project in Korea

\section{CONCLUSION}

The development of an improved installation procedure and schedule is one of the most important technologies for RVI modularization. The improved installation

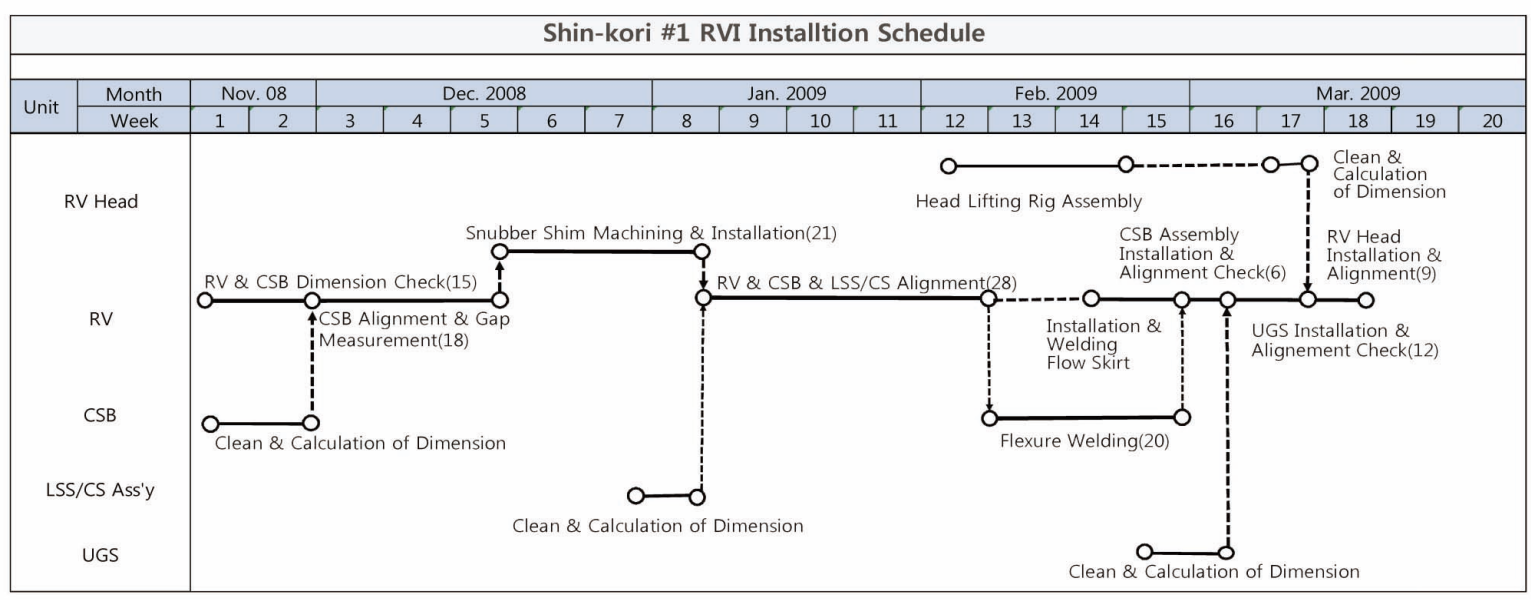

Fig. 12. Existing RVI Installation Schedule

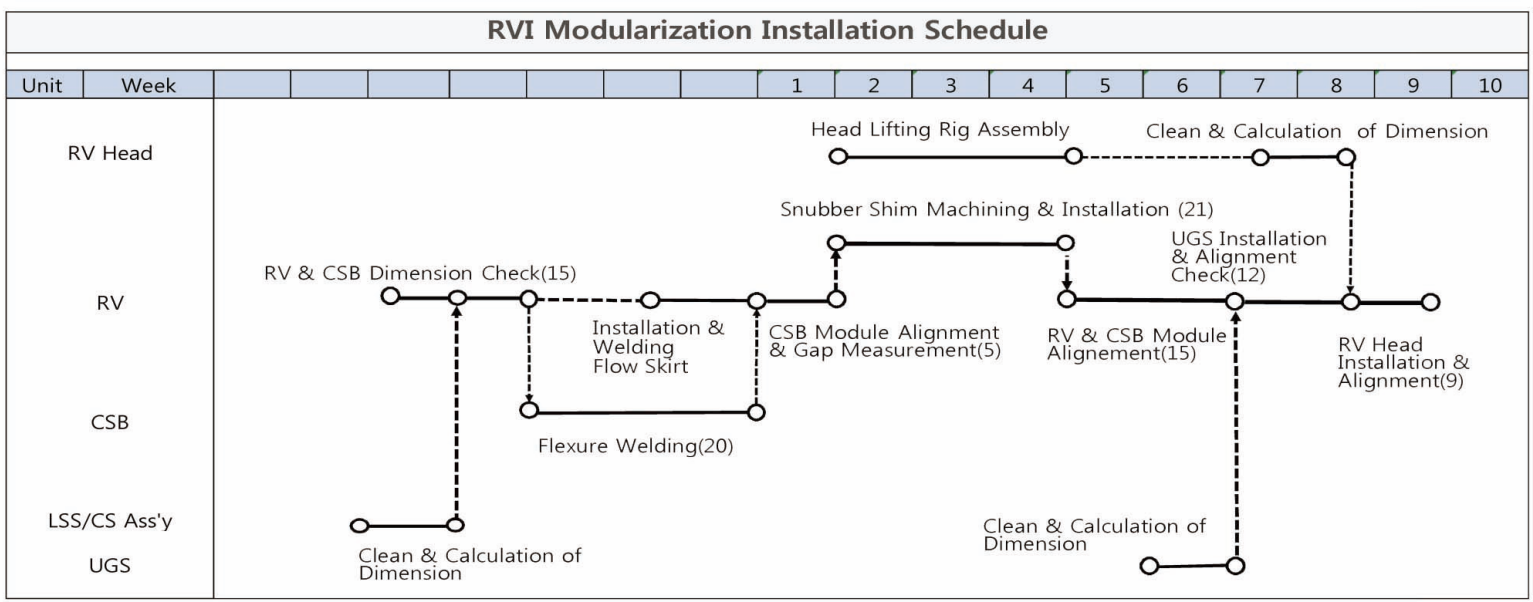

Fig. 13. Developed RVI Modularization Installation Schedule 
procedure and schedule developed here can be used at nuclear power plant construction sites. We validated the improved installation procedure through an experiment using a verified remote measurement system and then manufactured mockup.

On the basis of these studies, technologies for RVI modularization using the improved installation procedure and schedule will be applied to the construction project of the Shin-Ulchin \#1 and \#2 nuclear power plants using the APR1400 in Korea

\section{REFERENCES}

[ 1] Korea Hydro \& Nuclear Power Company, Construction Study Report for Development of Next Generation Reactor, TR.A99NJ13.P2002.Shin2, pp. 633-672, Korea Hydro \& Nuclear Power Company, 2002.

[2] ABB-CE, Support Work Agreement Work Order Delivery, H-4, Korea Electric Power Corporation, 1995.

[ 3 ] Jae-Gon Lee, Do-Young Ko, Yong-Chul Kang, A Study on the Remote Measuring Scheme for Modularization, Korea Nuclear Society Autumn Meeting, Kyeongju, 2006.

[ 4 ] Do-Young Ko, Jae-Gon Lee, Yong-Chul Kang, Sung-Hwan Kim, Development of a measurement system of gap between CSB and RV to shorten a nuclear reactor installation period, Nuclear Engineering and Design 239, pp. 495-500, 2009.

[ 5 ] Korea Hydro \& Nuclear Power Company, The Development of Modularization Technology for Reactor Internals, TRS05NJ02-J2009-58, pp. 26-135, Korea Hydro \& Nuclear Power Company, 2009.

[6] Mun, T.-Y., Sun, W.-S., Kim, K.-K., Lee, U.-K., A Study on the Construct ability of Steel Plate Concrete Structure for Nuclear Power Plant, Proceedings of the Korean Nuclear Society Spring Meeting, Daejeon, Korea, 2008.

[ 7 ] Mun, T.-Y., Kim, K.-K., Sun, W.-S., Kim, T.-Y., Hwang, G.-H., Design development of steel plate concrete modularization for the advanced PWR in Korea, The 16th pacific basin nuclear conference, Tokyo, Japan, 2008.

[ 8 ] Noh, S.-H., Lee, H.-W., Kim, C.-H., Development of the
SC module construction for nuclear power plants in Korea, The 16th pacific basin nuclear conference, Tokyo, Japan, 2008.

[9] Ricciuti, R., Fairclough, N., Hiebert, L., Elgohary, M., Yu, S.K.W., ACR constructability : increasing confidence in project objectives, The 12th international conference on nuclear engineering, Arlington, Virginia, United States, 2004.

[10] Ijichi, H., Yamashita, T., Tsutagawa, M., Mori, H., Ooshima, N., Miura, J., Kanechika, M., Miura, N., Development of Advanced Concept for Shortening Construction Period of ABWR Plant, The 10th international conference on nuclear engineering, Arlington, Virginia, United States, 2002.

[11] Elgohary, M., Fairclough, N., The ACR : Advanced design features for a short construction schedule, The 17 th international conference on structural mechanics in reactor technology, Brno, Czech Republic, 2003.

[12] Elgohary, M., Choy, E., Yu, S.K.W., Advanced construction methods in ACR, Canadian Nuclear Society Bulletin, Vol. 23 Issue 4, pp. 33-36, 2002.

[13] Korea Electric Power Research Institute, Construct ability Improvement for Nuclear Power Plants, TR-95ZJ02-97-41, Korea Electric Power Research Institute, 1997.

[14] Sieradzki, F. H., Optoelectronic inventory system for special nuclear material, SAND-93-2750, Sandia National Labs., Albuquerque, NM, United States, 1994.

[15] Yee, F., Byrne, J., Soulard, M., Moleschi, R., Akagi, K., Report of ACR-1000-Designed for constructability, International conference on opportunities and challenges for water cooled reactors in the 21 century, Vienna, Austria, 2009.

[16] Lee, Y.-Y., Kim, D.-G., Development of combined modularization technology for APR+ (Advanced Power Reactor) in Korea, Report of international conference on opportunities and challenges for water cooled reactors in the 21 century, Vienna, Austria, 2009.

[17] Do-Young Ko, Jae-Gon Lee, Development of a Remote Measurement System for the gap between RV and CSB for RVI-modularization, Nuclear Engineering and Design 240, pp. 2912-2918, 2010. 